\title{
Método de colheita e superação de dormência na qualidade fisiológica de sementes de Cassia ferruginea
}

\section{Methods for harvesting and breaking the dormancy of Cassia ferruginea seeds}

\author{
Cibele Chalita Martins ${ }^{1 *}$; Carla Gomes Machado²; \\ Adriana Martinelli-Seneme ${ }^{3}$; Claudemir Zucareli ${ }^{4}$
}

\begin{abstract}
Resumo
O método de colheita dos frutos deve ser adequado às características de cada espécie e permitir a obtenção de sementes com máxima qualidade. Sementes de Cassia ferruginea apresentam dormência devido à impermeabilidade do tegumento. Este trabalho teve o objetivo de determinar os métodos de colheita e de superação de dormência mais favoráveis à qualidade fisiológica de sementes de $C$. ferruginea. O trabalho foi conduzido em dois anos. No primeiro ano, os frutos foram colhidos no chão e as sementes foram submetidas aos seguintes tratamentos de superação de dormência: testemunha (1), escarificação mecânica em lixa número 220 (2), $\mathrm{H}_{2} \mathrm{O}$ quente por 5 minutos (temperaturas inicial e final de $82{ }^{\circ} \mathrm{C}$ e $69^{\circ} \mathrm{C}$ respectivamente) (3) e por 15 minutos (temperaturas inicial e final de $82{ }^{\circ} \mathrm{C}$ e $51{ }^{\circ} \mathrm{C}$, respectivamente), escarificação química com $\mathrm{H}_{2} \mathrm{SO}_{4}(95 \%)$ por 20, 30, 40, 50, 60, 70 e 80 minutos. No segundo ano as sementes foram colhidas no chão e na planta e as sementes foram submetidas aos tratamentos 1, 2, 3 e escarificação com $\mathrm{H}_{2} \mathrm{SO}_{4}$ por 30, 45 e 60 minutos (períodos de imersão em $\mathrm{H}_{2} \mathrm{SO}_{4}$ selecionados com base na germinação do experimento anterior). As sementes obtidas de frutos colhidos no chão ou na planta apresentam resposta diferenciada aos tratamentos de superação de dormência. Para a obtenção de sementes de $C$. ferruginea com máxima qualidade fisiológica, os frutos devem ser colhidos no chão e as sementes devem ser submetidas a escarificação com lixa ou $\mathrm{H}_{2} \mathrm{SO}_{4}$ por 30 a 60 min.

Palavras-chave: Sistema de colheita, germinação, sementes duras
\end{abstract}

\begin{abstract}
The harvesting method of fruits of tree species should be adequate to obtain seeds of maximum physiological quality. When present, the dormancy of Cassia ferruginea seeds is due to seed coat impermeability to water. This research work viewed to find the best methods both for the harvesting and for the breaking of dormancy of seeds of that species. The experiment was conducted during two years. In the first, fruits shed from the mother plant and laying on the ground were picked and their seeds submitted to the following treatments: 1. control, 2. mechanical scarification of the seeds with sandpaper no. 220,3 . hot water for 5 minutes (initial and final temperatures of 82 and $69^{\circ} \mathrm{C}$, respectively), 4. hot water for 15 minutes (initial and final temperatures of 82 and $51{ }^{\circ} \mathrm{C}$, respectively),
\end{abstract}

\footnotetext{
1 Eng ${ }^{\mathrm{o}}$ Agro , Prof $\mathrm{f}^{\mathrm{a}}$. Dra . Universidade Estadual Paulista "Júlio de Mesquita Filho", UNESP, Faculdade de Ciências Agrárias e Veterinárias de Jaboticabal, Via Acesso Prof. Paulo Donato Castellane, s/n, CEP 14884-900, Jaboticabal, SP. E-mail: cibele@ fcav.unesp.br

${ }^{2}$ Eng $^{\mathrm{o}}$ Agr $^{\mathrm{o}}$, Prof ${ }^{\mathrm{a}}$. Dr ${ }^{\mathrm{a}}$. da Unidade Universitária de Palmeiras de Goiás, Universidade Estadual de Goiás, UEG. E-mail: carlagomesmachado@gmail.com

${ }^{3}$ Eng $^{\circ}$ Agr $^{\circ}$, Prof ${ }^{\mathrm{a}}$. Dr ${ }^{\mathrm{a}}$. da Faculdades Integradas Espírita, FACIBEN, Curitiba, PR. E-mail: adriana.seneme@hotmail.com

${ }^{4}$ Eng $^{\mathrm{o}}$ Agr $^{\circ}$, Prof. Dr. do Dept ${ }^{\circ}$ de Agronomia da Universidade Estadual de Londrina, UEL, Londrina, PR. E-mail: claudemircca@ uel.br

* Autor para correspondência
} 
5. chemical scarification with $\mathrm{H}_{2} \mathrm{SO}_{4}(95 \%)$ for $20,30,40,50.60,70$, and 80 minutes. In the second year, seeds were submitted to treatments 2,3 , and 4 whereas acid scarification was applied for 30,45 , and 60 minutes. The results showed that seeds picked from the ground and those taken directly from the mother plant differ in their response to the dormancy breaking procedure. The results also showed that the seeds picked from the ground are better than those harvested directly from the plant and that, when dormant, the best results are attained when seeds are either submitted to mechanical scarification or chemical scarification with sulfuric acid for periods between 30 and 60 minutes.

Key words: Harvesting system, germination, hard seeds

\section{Introdução}

A Cassia ferruginea (Schrad) Schrad ex DC, também conhecida como tapira-coiana, chuva-deouro e canafístula-de-besouro é uma espécie nativa, pertencente à família Fabaceae-Caesalpinioideae, com ocorrência do nordeste ao sul do Brasil. Além da utilização ornamental, sua madeira pode ser empregada em vigamentos, caibros, rodapés, obras internas e palitos de fósforo (LORENZI, 2002). As sementes de Cassia spp apresentam dormência decorrente da impermeabilidade do tegumento, que é a causa mais comum de dormência nas sementes de leguminosas (LOPES et al. 1998; RODRIGUES; AGUIAR; SADER, 1990; JELLER; PEREZ, 1999; FOWLER; BIANCHETTI, 2000).

A tecnologia de sementes tem o objetivo de adaptar ou criar métodos tecnológicos adequados para determinada espécie para ter-se como resultado final uma melhoria no padrão de qualidade desta, desde a colheita até a semeadura. Assim, o método de colheita dos frutos deve ser adequado às características de cada espécie arbórea para permitir a obtenção de sementes com máxima germinação e vigor (NOGUEIRA; MEDEIROS, 2007; MARTINS et al., 2008). As sementes de $C$. ferruginea podem ser colhidas diretamente nas árvores ou no chão após a queda dos frutos, pois nesta espécie as vagens são relativamente grandes, pesadas e indeiscentes, caindo ao solo sem se abrir (NOGUEIRA; MEDEIROS, 2007).

A colheita direta das árvores ocorre mediante corte e derrubada dos frutos e, dependendo da altura, necessita da escalada nas plantas. A viabilidade desse método é função da qualidade e quantidade da semente a ser colhida e disponibilidade de mão- de-obra treinada (NOGUEIRA; MEDEIROS, 2007). A colheita do chão consiste na catação de frutos com sementes nas proximidades da árvore mãe. Para maior facilidade de coleta pode-se utilizar lonas, encerados de polietileno, ou pode ser necessária uma capina de limpeza ao redor das árvores matrizes onde serão recolhidos os frutos e as sementes (NOGUEIRA; MEDEIROS, 2007).

No campo e após a colheita, as sementes de C. ferruginea costumam ser atacadas por insetos como Zabrotes interstitialis, Pygiopachymerus lineola (Coleoptera: Bruchidae) e um Lepidoptera (Pyralidae) (SANTOS et al., 1994) e, por esse motivo, recebe o nome comum de canafístulade-besouro. A permanência dos frutos no chão pode expor por mais tempo a semente à predação, reduzindo a produção e a qualidade física e fisiológica das sementes (MARTINS et. al, 2008). No entanto, se a danificação causada pelos insetos em sementes duras for superficial, não afetando o eixo embrionário, este seria um método natural de superação de dormência e promoção da germinação (TOMAZ; KESTRING; ROSSI, 2007).

A dormência das sementes torna-se um problema para os viveiristas, pois causa atraso e desuniformidade na germinação e na produção de mudas. Na família Fabacea a causa de dormência mais comum é decorrente da impermeabilidade do tegumento a água. No entanto, existem vários tratamentos que podem ser usados com êxito para superar esse tipo de dormência de sementes de Cassia spp, tais como: escarificação mecânica por abrasão ou química com $\mathrm{H}_{2} \mathrm{SO}_{4}$, eficientes para Cassia fistula L., Cassia nodosa Buch.-Ham. ex Roxb, Cassia leptophylla Vogel, Cassia grandis L, Cassia excelsa L., Cassia bicapsulares L., Cassia 
speciosa Schrad., Cassia javanica L. (LOPES et al. 1998; RODRIGUES; AGUIAR; SADER, 1990; JELLER; PEREZ, 1999; FOWLER; BIANCHETTI, 2000), escarificação química com $\mathrm{H}_{2} \mathrm{SO}_{4}$ para $C$. grandis e imersão em água à temperatura inicial de $100^{\circ} \mathrm{C}$, seguida da permanência por 24 horas imersa para sementes de Cassia siamea Lamk. (FOWLER; BIANCHETTI, 2000). O tempo de aplicação e a eficiência dos tratamentos de superação de dormência dependem da espécie e da origem das sementes (MARTINS; NAKAGAWA, 2008).

O presente trabalho teve como objetivo determinar os métodos de colheita e de superação de dormência mais favoráveis à qualidade fisiológica de sementes de $C$. ferruginea.

\section{Material e Métodos}

Frutos de C. ferruginea foram colhidos em 15 árvores-matriz no Campus da UNESP, Faculdade de Ciências Agronômicas, em Botucatu, São Paulo. O trabalho foi conduzido em duas etapas. Na primeira, os frutos foram colhidos no chão no ano de 2000 e após extração e limpeza, as sementes foram submetidas aos seguintes tratamentos de superação de dormência: testemunha - sementes sem tratamento; escarificação mecânica - fricção manual da semente em lixa número 220 , realizada por dois técnicos de laboratório, com experiências de trabalho distintas; água quente por 5 e 15 minutos - imersão das sementes em água, com temperaturas inicial de $82{ }^{\circ} \mathrm{C}$ e final de $69{ }^{\circ} \mathrm{C}$ para 5 minutos e de $51^{\circ} \mathrm{C}$ para 15 minutos, seguida por secagem à sombra; Escarificação química por 20, 30, 40, 50, 60, 70 e 80 minutos - imersão das sementes em ácido sulfúrico $36 \mathrm{~N}$, 95\%, pelo tempo previsto, seguida de lavagem em água corrente e secagem à sombra.

As sementes foram avaliadas pelo teste de germinação com quatro subamostras de 50 sementes, em papel toalha (RP) umedecido com água na proporção de duas vezes e meia a massa do substrato seco (BRASIL, 2009), à temperatura $25^{\circ} \mathrm{C}$ e oito horas de luz, sendo a contagem das plântulas realizada no sétimo e $14^{\circ}$ dia após a semeadura, quando foram calculadas as porcentagens de plântulas normais, anormais, sementes dormentes (duras) e mortas. Foi também avaliada a primeira contagem, realizada aos sete dias após a semeadura, contabilizando-se o número de plântulas normais, o que reflete a velocidade de germinação, um indicativo de vigor.

$\mathrm{Na}$ segunda etapa do trabalho, os frutos foram colhidos no ano de 2003, no chão e na árvore e as sementes foram extraídas. Para a comparação da colheita no chão e na planta quanto aos danos físicos causados por insetos às sementes foi calculado: a) o rendimento de sementes sujas e de sementes limpas por quilograma de vagem colhida. Para isso, duas amostras de um quilo de vagens de cada método de colheita tiveram todas as sementes extraídas e pesadas em balança de duas casas decimais compondo o peso de sementes sujas. Essas sementes foram imersas em água por 10 minutos e as que boiaram (chochas e mal formadas) foram descartadas. As sementes que afundaram foram submetidas à catação manual para a retirada das sementes infestadas por insetos e com danos visíveis.

As sementes remanescentes foram pesadas para compor a porção sementes limpas da amostra; b) Exame de sementes infestadas (danificadas por insetos). Para essa determinação foi adotada a metodologia estabelecida pelas Regras para Análise de Sementes (BRASIL, 2009), utilizando-se duas repetições de 100 sementes da porção sementes limpas da cada método de colheita, examinadas individualmente antes e após a imersão em água por 24 horas. Para possibilitar esta embebição as sementes foram escarificadas com lixa. Após a embebição as sementes foram cortadas individualmente de forma a assegurar uma perfeita observação e registro do número de sementes que se apresentassem perfuradas ou com ovo, larva, lagarta, pupa ou inseto adulto. O resultado constou da média das sementes danificadas por insetos das 
duas repetições e expresso em porcentagem, com uma casa decimal.

As sementes limpas do chão e da planta foram submetidas aos tratamentos testemunha, escarificação mecânica, água quente por 5 minutos e escarificação em ácido sulfúrico por 30, 45 e 60 minutos. Esses tratamentos e os testes de germinação e primeira contagem seguiram a mesma metodologia descrita na primeira etapa do trabalho.

O experimento foi instalado em um delineamento estatístico inteiramente casualizado e com quatro repetições de 50 sementes e a análise foi processada utilizando-se o software SISVAR. Na primeira etapa da pesquisa foram avaliados 12 tratamentos. $\mathrm{Na}$ segunda etapa da pesquisa os tratamentos foram dispostos em um esquema fatorial $2 \times 6$, sendo dois métodos de colheita e seis tratamentos de superação da dormência. Esses últimos foram selecionados na primeira etapa do trabalho. Os dados de plântulas anormais foram transformados em arco seno ( $(\mathrm{x}+$ 1)/100) ${ }^{1 / 2}$ segundo o teste de Cocrahn (BANZATTO; KRONKA, 2006). As médias apresentadas são dos dados originais.

\section{Resultados e Discussão}

$\mathrm{Na}$ primeira etapa do trabalho, verificou-se que o tratamento de imersão em $\mathrm{H}_{2} \mathrm{SO}_{4}$ por $50 \mathrm{~min}$ apresentou a promoção máxima da germinação das sementes de $C$. ferruginea em valores absolutos (Tabela 1), embora esse tempo de imersão não tenha diferido estatisticamente dos períodos de 30, 40 e 60 min para plântulas normais e 30 e 40 min para o teste da primeira contagem. Estes resultados podem ser atribuídos ao efeito favorável à superação da dormência, ou seja, sem causar danos a qualidade fisiológica das sementes, decorrente da imersão das mesmas em $\mathrm{H}_{2} \mathrm{SO}_{4}$ por $50 \mathrm{~min}$, pois este tratamento reduziu a porcentagem de sementes dormentes de $88 \%$ para $8 \%$ e, adicionalmente, apresentou os menores valores estatísticos de sementes mortas e plântulas anormais, similares à testemunha.

Embora a escarificação em $\mathrm{H}_{2} \mathrm{SO}_{4}$ por períodos iguais ou superiores a $60 \mathrm{~min}$ tenham tornado nula a dormência das sementes, verificou-se que o aumento do tempo de imersão em ácido intensificou os danos às sementes. Assim, quando comparados à escarificação em $\mathrm{H}_{2} \mathrm{SO}_{4}$ por 50 min, os tratamentos por tempos maiores de imersão promoveram o aumento da incidência de plântulas anormais e de sementes mortas e reduções graduais da velocidade de germinação (primeira contagem) e da porcentagem de germinação. De modo oposto, a escarificação ácida por períodos menores que 50 min não causaram danos à sementes, mas o tempo de imersão por 20 min foi insuficiente para a obtenção de valores máximos de germinação. Os resultados favoráveis à promoção da germinação devido aos tratamentos de escarificação com ácido sulfúrico foram similares aos relatados para sementes de outras espécies de Cassia (LOPES et al., 1998; RODRIGUES; AGUIAR; SADER, 1990; JELLER; PEREZ, 1999).

Apesar da eficiência dos tratamentos com ácido sulfúrico, sua utilização apresenta algumas desvantagens, tais como o perigo de queimaduras ao técnico ou operário que executa a escarificação devido a sua ação corrosiva, a elevação da temperatura e respingos quando em contato com a água, dificuldades na utilização para volumes relativamente grandes de sementes e alto custo. Por isso, em viveiros, a imersão em água quente é um método de superação de dormência mais empregado devido à facilidade do tratamento, baixo custo e pequeno risco ao trabalhador (FOWLER; BIANCHETTI, 2000; ALVES et al., 2007). 
Tabela 1. Porcentagem de plântulas normais, anormais, sementes dormentes, mortas e vigor avaliado pelo teste de germinação de sementes de Cassia ferruginea após tratamentos de superação de dormência, referentes à primeira etapa do trabalho realizada no ano de 2000.

\begin{tabular}{|c|c|c|c|c|c|}
\hline \multirow{2}{*}{$\begin{array}{c}\text { Tratamentos de superação } \\
\text { de dormência }\end{array}$} & \multicolumn{2}{|c|}{ Plântulas (\%) ${ }^{(1)}$} & \multicolumn{2}{|c|}{ Sementes $(\%)$} & \multirow{2}{*}{$\begin{array}{c}\text { Primeira } \\
\text { contagem }(\%)\end{array}$} \\
\hline & Normais & anormais $^{(2)}$ & Dormentes & mortas & \\
\hline Testemunha & $6 \mathrm{f}$ & $1 \mathrm{c}$ & 88 a & 6 ef & $4 \mathrm{f}$ \\
\hline Lixa - técnico 1 & $53 \mathrm{~d}$ & $2 \mathrm{c}$ & $33 \mathrm{~b}$ & 13 cde & $49 \mathrm{~d}$ \\
\hline Lixa - técnico 2 & $15 \mathrm{f}$ & $1 \mathrm{c}$ & $0 \mathrm{e}$ & 84 a & $11 \mathrm{f}$ \\
\hline $\mathrm{H}_{2} \mathrm{O}$ quente $-5 \mathrm{~min}$ & $9 \mathrm{f}$ & $0 \mathrm{c}$ & 83 a & 9 def & $7 \mathrm{f}$ \\
\hline $\mathrm{H}_{2} \mathrm{O}$ quente $-15 \mathrm{~min}$ & $9 \mathrm{f}$ & $0 \mathrm{c}$ & $87 \mathrm{a}$ & $5 \mathrm{f}$ & $5 \mathrm{f}$ \\
\hline $\mathrm{H}_{2} \mathrm{SO}_{4-} 20 \mathrm{~min}$ & $67 \mathrm{bc}$ & $0 \mathrm{c}$ & $28 \mathrm{~b}$ & $6 \mathrm{ef}$ & $65 \mathrm{bc}$ \\
\hline $\mathrm{H}_{2} \mathrm{SO}_{4-} 30 \mathrm{~min}$ & $78 \mathrm{ab}$ & $0 \mathrm{c}$ & $18 \mathrm{c}$ & $5 \mathrm{f}$ & $77 \mathrm{ab}$ \\
\hline $\mathrm{H}_{2} \mathrm{SO}_{4-} 40 \mathrm{~min}$ & $77 \mathrm{ab}$ & $1 \mathrm{c}$ & $14 \mathrm{~cd}$ & 8 def & $74 \mathrm{abc}$ \\
\hline $\mathrm{H}_{2} \mathrm{SO}_{4-} 50 \mathrm{~min}$ & 86 a & $1 \mathrm{c}$ & 8 de & $6 \mathrm{f}$ & 82 a \\
\hline $\mathrm{H}_{2} \mathrm{SO}_{4-} 60 \mathrm{~min}$ & $73 \mathrm{ab}$ & $12 \mathrm{~b}$ & $0 \mathrm{e}$ & $15 \mathrm{~cd}$ & $63 \mathrm{c}$ \\
\hline $\mathrm{H}_{2} \mathrm{SO}_{4-} 70 \mathrm{~min}$ & $56 \mathrm{~cd}$ & $25 \mathrm{a}$ & $0 \mathrm{e}$ & $19 \mathrm{c}$ & $48 \mathrm{~d}$ \\
\hline $\mathrm{H}_{2} \mathrm{SO}_{4-} 80 \mathrm{~min}$ & $36 \mathrm{e}$ & $35 \mathrm{a}$ & $0 \mathrm{e}$ & $30 \mathrm{~b}$ & $29 \mathrm{e}$ \\
\hline $\mathrm{CV} \%$ & 11,07 & 23,93 & 11,37 & 17,72 & 11,48 \\
\hline
\end{tabular}

(1) Para cada característica avaliada, médias seguidas pela mesma letra na coluna não diferem estatisticamente entre si pelo teste Tukey $(\mathrm{P}<0,05)$.

${ }^{(2)} \mathrm{O}$ procedimento estatístico foi realizado com os dados transformados em arco seno $((\mathrm{x}+1) / 100)^{1 / 2}$ e as médias apresentadas são dos dados originais.

Fonte: Elaboração dos autores.

Entretanto, neste trabalho, a imersão em água quente mostrou-se ineficiente em ambos os períodos de imersão avaliados (5 e $15 \mathrm{~min}$ ) com resultados semelhantes à testemunha, em todos os parâmetros: plântulas normais, anormais, sementes mortas, dormentes e primeira contagem, não sendo indicada para sementes de C. ferruginea (Tabelas 1, 2 e 3), de modo similar ao verificado para sementes de Cassia excelsa Scharad (JELLER; PEREZ, 1999), Bauhinia divaricata L. (ALVES, et al., 2004) e Stryphnodendron adstringens L. (MARTINS; NAKAGAWA, 2008).

No entanto, a eficiência deste tratamento pode depender da espécie, pois para sementes de C. bicapsulares, C. speciosa e C. javanica (RODRIGUES; AGUIAR; SADER, 1990) e Caesalpinia pyramidalis Tul. (ALVES et al., 2007) foram verificados resultados contrários, ou seja, favoráveis à germinação utilizando-se água quente.

Quanto à eficiência da escarificação das sementes com lixa, pôde-se verificar em comparação à testemunha, que o procedimento realizado pelo técnico 1 desgastou o tegumento das sementes de modo a promover a superação a dormência e aumentar a porcentagem e velocidade de germinação, sem causar danos que elevassem as porcentagens de plântulas anormais e sementes mortas em níveis estatisticamente significativos. No entanto, o técnico 2 foi menos habilidoso e eficiente, pois embora seu procedimento de escarificação tenha superado totalmente a dormência das sementes, causou danos drásticos que elevaram ao máximo a porcentagem de sementes mortas e reduziram a velocidade e porcentagem de germinação a valores estatisticamente semelhantes à testemunha. 
Portanto, a escarificação com lixa foi um tratamento cuja eficiência mostrou ser dependente da habilidade e prática do técnico que executa o procedimento (Tabela 1). Este pode ser considerado um método trabalhoso e viável apenas para pequenos volumes de sementes, no entanto costuma ser utilizado como referência em trabalhos de superação de dormência de sementes com tegumento impermeável e, para sementes de $C$. bicapsulares, C. speciosa e C. javanica, mostrou-se eficaz na promoção da germinação (RODRIGUES; AGUIAR; SADER, 1990).

$\mathrm{Na}$ segunda etapa do trabalho, verificou-se que o rendimento das vagens do chão e da planta foi de 66 e $72 \mathrm{~g}$ de sementes sujas e 52 e $53 \mathrm{~g}$ de sementes limpas por quilograma de vagem, respectivamente. As sementes limpas de vagens do chão e da planta apresentaram porcentagens similares de infestação por insetos, de 5,5 e 6,5\%, respectivamente. Considerando-se o rendimento de sementes sujas, a colheita na planta aparentemente possibilitaria uma maior produção, mas em termos de sementes de alta qualidade, bem formadas, sem danos e sem insetos, aspectos verificados pela determinação das sementes limpas e sementes infestadas, os dois tipos de colheita foram similares.

A avaliação desses resultados permite inferir que os danos causados pela exposição das sementes ao ataque de insetos não foram influenciados pelo local de permanência dos frutos antes da colheita. A determinação de sementes danificadas por insetos faz-se importante, pois a infestação de sementes no campo pode causar prejuízos à qualidade do lote com o comprometimento da comercialização, devido à rápida proliferação dos insetos após a colheita, durante o armazenamento (BRASIL, 2009).
$\mathrm{Na}$ Tabela 2, verificou-se que a porcentagem de sementes mortas apesar de não ter sido afetada pelo método de colheita, sofreu influência do tratamento de superação de dormência, verificando-se aumento significativo de sementes mortas após a imersão em água quente por $5 \mathrm{~min}$. Esses dados, analisados em conjunto com os apresentados na Tabela 3, permitem inferir que o tratamento de imersão em água quente promoveu a superação da dormência, mas causou a morte das sementes. Em comparação à testemunha, a imersão em água quente não promoveu alterações significativas na porcentagem de plântulas normais e anormais, ou na velocidade de germinação. Assim, esses resultados corroboram os obtidos na primeira etapa do trabalho quanto à ineficiência da utilização desse método para a promoção da germinação, independente do método de colheita adotado.

Todos os demais tratamentos foram eficientes na superação da dormência, resultando no aumento da porcentagem de plântulas normais e velocidade de germinação, sem causar a morte das sementes (Tabelas 2 e 3), mas a intensidade de resposta a esses tratamentos foi influenciada pelo método de colheita.

Assim, a escarificação com lixa somente possibilitou resultados máximos de velocidade e porcentagem de germinação quando foi aplicada às sementes colhidas no chão (Tabela 3 ). Esse método de colheita também promoveu máximos valores da velocidade de germinação de sementes escarificadas com $\mathrm{H}_{2} \mathrm{SO}_{4}$ por 30 min. De modo diverso, para as sementes colhidas na planta, foram necessários tempos maiores de escarificação em $\mathrm{H}_{2} \mathrm{SO}_{4}$, de 45 e 60 min, para a obtenção de valores máximos na primeira contagem. 
Tabela 2. Porcentagem de sementes mortas avaliado pelo teste de germinação de sementes de Cassia ferruginea de diferentes métodos de colheita e após tratamentos de superação de dormência, referentes à segunda etapa do trabalho realizada no ano de 2003.

\begin{tabular}{ccc}
\hline & Tratamentos & Sementes Mortas (\%) \\
\hline \multirow{2}{*}{ Colheita } & No pé & 8 A \\
& No chão & 6 A \\
\hline \multirow{3}{*}{ Tratamentos para } & Testemunha & $3 \mathrm{~B}$ \\
superação da dormência & Lixa & $6 \mathrm{~B}$ \\
& $\mathrm{H}_{2} \mathrm{O}$ quente -5 min & $23 \mathrm{~A}$ \\
& $\mathrm{H}_{2} \mathrm{SO}_{4}-30$ min & $4 \mathrm{~B}$ \\
& $\mathrm{H}_{2} \mathrm{SO}_{4}-45$ min & $4 \mathrm{~B}$ \\
& $\mathrm{H}_{2} \mathrm{SO}_{4}-60$ min & $3 \mathrm{~B}$ \\
\hline
\end{tabular}

Para cada característica avaliada, médias seguidas pela mesma letra na coluna não diferem estatisticamente entre si pelo teste Tukey $(\mathrm{P}<0,05)$.

Fonte: Elaboração dos autores.

Tabela 3. Interação dos métodos de colheita e dos tratamentos de superação de dormência sobre a porcentagem de plântulas normais, sementes dormentes e vigor avaliado pelo teste de germinação de sementes de Cassia ferruginea, referentes à segunda etapa do trabalho realizada no ano de 2003.

\begin{tabular}{|c|c|c|c|c|c|c|c|}
\hline \multirow{2}{*}{$\begin{array}{c}\text { Parâmetros } \\
\text { avaliados (\%) }\end{array}$} & \multirow{2}{*}{$\begin{array}{c}\text { Tratamentos para } \\
\text { superação de dormência }\end{array}$} & \multicolumn{5}{|c|}{ Colheita $^{(1)}$} & \multirow{2}{*}{$\mathrm{CV}(\%)$} \\
\hline & & \multicolumn{3}{|c|}{ No pé } & \multicolumn{2}{|c|}{ No chão } & \\
\hline \multirow{6}{*}{$\begin{array}{l}\text { Primeira } \\
\text { Contagem }\end{array}$} & Testemunha & 3 & $\mathrm{~d}$ & $\mathrm{~A}$ & & c $\mathrm{A}$ & \multirow{6}{*}{20,02} \\
\hline & Lixa & 61 & bc & $\mathrm{B}$ & 93 & a A & \\
\hline & $\mathrm{H}_{2} \mathrm{O}$ quente -5 min & 0 & d & A & 0 & c A & \\
\hline & $\mathrm{H}_{2} \mathrm{SO}_{4}-30 \mathrm{~min}$ & 49 & c & $\mathrm{B}$ & 93 & a $\mathrm{A}$ & \\
\hline & $\mathrm{H}_{2}^{2} \mathrm{SO}_{4}^{4}-45 \mathrm{~min}$ & 75 & $\mathrm{ab}$ & $\mathrm{A}$ & 63 & b $\mathrm{B}$ & \\
\hline & $\mathrm{H}_{2}^{2} \mathrm{SO}_{4}^{4}-60 \mathrm{~min}$ & 85 & $\mathrm{a}$ & $\mathrm{A}$ & 65 & $\mathrm{~b} \quad \mathrm{~B}$ & \\
\hline \multirow{6}{*}{$\begin{array}{l}\text { Plântulas } \\
\text { Normais }\end{array}$} & Testemunha & 6 & $\mathrm{c}$ & $\mathrm{A}$ & 8 & $\mathrm{~b} \quad \mathrm{~A}$ & \multirow{6}{*}{14,20} \\
\hline & Lixa & 65 & $\mathrm{~b}$ & $\mathrm{~B}$ & 93 & a $\mathrm{A}$ & \\
\hline & $\mathrm{H}_{2} \mathrm{O}$ quente $-5 \mathrm{~min}$ & 1 & $\mathrm{c}$ & A & 0 & b A & \\
\hline & $\mathrm{H}_{2} \mathrm{SO}_{4}-30 \mathrm{~min}$ & 78 & $a b$ & $\mathrm{~B}$ & 96 & a A & \\
\hline & $\mathrm{H}_{2}^{2} \mathrm{SO}_{4}^{4}-45 \mathrm{~min}$ & 82 & $\mathrm{ab}$ & $\mathrm{B}$ & 96 & a A & \\
\hline & $\mathrm{H}_{2}^{2} \mathrm{SO}_{4}^{4}-60 \mathrm{~min}$ & 92 & $\mathrm{a}$ & $\mathrm{A}$ & 95 & a $\mathrm{A}$ & \\
\hline \multirow{6}{*}{$\begin{array}{l}\text { Plântulas } \\
\text { Anormais }^{(2)}\end{array}$} & Testemunha & 3 & $\mathrm{ab}$ & A & & a $\mathrm{A}$ & \multirow{6}{*}{41,44} \\
\hline & Lixa & 5 & $a b$ & $\mathrm{~A}$ & 0 & a $B$ & \\
\hline & $\mathrm{H}_{2} \mathrm{O}$ quente $-5 \mathrm{~min}$ & 0 & $\mathrm{~b}$ & A & 0 & a A & \\
\hline & $\mathrm{H}_{2} \mathrm{SO}_{4}-30 \mathrm{~min}$ & 9 & $\mathrm{a}$ & A & 0 & a $\mathrm{B}$ & \\
\hline & $\mathrm{H}_{2}^{2} \mathrm{SO}_{4}^{4}-45 \mathrm{~min}$ & 10 & $\mathrm{a}$ & $\mathrm{A}$ & 0 & a $\mathrm{B}$ & \\
\hline & $\mathrm{H}_{2}^{2} \mathrm{SO}_{4}^{4}-60 \mathrm{~min}$ & 4 & $\mathrm{ab}$ & $\mathrm{A}$ & 1 & a $\mathrm{A}$ & \\
\hline \multirow{6}{*}{$\begin{array}{l}\text { Sementes } \\
\text { Dormentes }\end{array}$} & Testemunha & 92 & $\mathrm{a}$ & $\mathrm{A}$ & 87 & $\begin{array}{ll}\mathrm{a} & \mathrm{A}\end{array}$ & \multirow{6}{*}{16,63} \\
\hline & Lixa & 22 & $\mathrm{c}$ & A & 6 & c $\mathrm{B}$ & \\
\hline & $\mathrm{H}_{2} \mathrm{O}$ quente $-5 \mathrm{~min}$ & 79 & $\mathrm{~b}$ & $\mathrm{~A}$ & 75 & $\mathrm{~b} \quad \mathrm{~A}$ & \\
\hline & $\mathrm{H}_{2} \mathrm{SO}_{4}-30 \mathrm{~min}$ & 6 & $\mathrm{~d}$ & $\mathrm{~A}$ & 5 & c $\mathrm{A}$ & \\
\hline & $\mathrm{H}_{2}^{2} \mathrm{SO}_{4}^{4}-45 \mathrm{~min}$ & 2 & $\mathrm{~d}$ & $\mathrm{~A}$ & 4 & c A & \\
\hline & $\mathrm{H}_{2}^{2} \mathrm{SO}_{4}^{4}-60 \mathrm{~min}$ & 0 & d & $\mathrm{A}$ & 3 & c A & \\
\hline
\end{tabular}

${ }^{(1)}$ Médias seguidas pela mesma letra, maiúscula na linha e minúscula na coluna não diferem entre si pelo teste de Tukey a 5\% de probabilidade.

${ }^{(2)} \mathrm{O}$ procedimento estatístico foi realizado com os dados transformados em arco seno.

$((\mathrm{x}+1) / 100)^{1 / 2}$ e as médias apresentadas são dos dados originais.

Fonte: Elaboração dos autores. 
Em comparação aos demais tratamentos, a escarificação das sementes com $\mathrm{H}_{2} \mathrm{SO}_{4}$, por 30, 45 e 60 min resultaram em valores máximos de germinação (plântulas normais). Adicionalmente, para os tempos de imersão de 30 e 45 min observou-se que sementes colhidas no chão apresentaram melhor desempenho germinativo que as colhidas na planta, o que pode ser verificado pela maior porcentagem de plântulas normais e, menor, de anormais.

Provavelmente a colheita no chão garantiria que todos os frutos colhidos apresentassem sementes com o processo de maturação concluído, pois a maturidade fisiológica ocorre antes da dispersão. Isso nem sempre ocorre para os frutos colhidos na planta, pois a espécie é pouco domesticada e apresenta desuniformidade de maturação. Observações similares foram relatadas para sementes Araucaria angustifolia (Bert.) O. Kuntze e verificadas em trabalho sobre método de colheita de frutos e sementes de Jacaranda cuspidifolia Mart. (NOGUEIRA; MEDEIROS, 2007; MARTINS et al., 2008).

\section{Conclusões}

Sementes obtidas de frutos colhidos no chão ou na planta apresentam resposta diferenciada aos tratamentos de superação de dormência.

Para a obtenção de sementes de $C$. ferruginea com máxima qualidade fisiológica, os frutos devem ser colhidos no chão e as sementes devem ser submetidas a escarificação com lixa ou $\mathrm{H}_{2} \mathrm{SO}_{4}$, por períodos entre 30 e $60 \mathrm{~min}$.

\section{Referências}

ALVES, A. U.; DORNELAS, C. S. M.; BRUNO, R. L. A.; ANDRADE, L. A.; ALVES, E. U. Superação da dormência em sementes de Bauhinia divaricata L. Acta Botânica Brasilica, São Paulo, v. 18, n. 4, p. 871-879, 2004.

ALVES, E. U.; CARDOSO, E. A.; BRUNO, R. L. A.; ALVES, A. U.; ALVES, A. U.; GALINDO, E. A.; BRAGA JUNIOR, J. M. Superação da dormência em sementes de Caesalpinia pyramidalis Tul. Revista Árvore, Viçosa, v. 31, n. 3, p. 405-415, 2007.
BANZATTO, D. A.; KRONKA, S. N. Experimentação agrícola. 4. ed. Funep: Jaboticabal, 2006. 237 p.

BRASIL. Ministério da Agricultura, Pecuária e Abastecimento. Secretaria de Defesa Agropecuária. Regras para análise de sementes. Brasília, 2009. 399 p.

FOWLER, A. J. P.; BIANCHETTI, A. Dormência em sementes florestais. Colombo: Embrapa Florestas, 2000. 27 p. (Embrapa Florestas. Documentos, 40).

JELLER, H.; PEREZ, S. C. J. G. A. Estudo da superação da dormência e da temperatura em sementes de Cassia excelsa Schrad. Revista Brasileira de Sementes, Campinas, v. 21, n. 1, p. 32-40, 1999.

LOPES, J. C.; CARPUCHO, N. T.; KLOHLING, B.; ZANOTTI, P. Germinação de sementes de espécies florestais de Caesalpinea ferrea Mart. ex Tul. var. leiostachya Benth., Cassia grandis L. e Samanea saman Merrill, após tratamento para superar a dormência. Revista Brasileira de Sementes, Brasília, v. 20, n. 1, p. 80-86, 1998.

LORENZI, H. Árvores brasileiras: manual de identificação e cultivo de plantas arbóreas nativas do Brasil. Nova Odessa: Instituto Plantarum, v. 1, 2002.

MARTINS, C. C.; BELISSÁRIO, L.; TOMAZ, C. A.; ZUCARELI, C. Condições climáticas, caracteristicas do fruto e sistema de colheita na qualidade fisiológica de sementes de jacarandá. Revista Árvore, Viçosa, v. 32, n. 4, p. 627-632, 2008.

MARTINS, C. C.; NAKAGAWA, J. Germinação de sementes de Stryphnodendron adstringens (Mart.) Coville de diferentes origens submetidas a tratamentos para superação de dormência. Revista Árvore, Viçosa, v. 32, n. 6, p. 1059-1067, 2008.

NOGUEIRA, A. C.; MEDEIROS, A. C. S. Coleta de sementes florestais nativas. Colombo: Embrapa Florestas, 2007. 11 p. (Embrapa Florestas. Circular Técnica, 144).

RODRIGUES, E. H. A.; AGUIAR, I. B.; SADER, R. Quebra de dormência de sementes de três espécies do gênero Cassia. Revista Brasileira Sementes, Brasília, v. 12, n. 2, p. 17-25, 1990.

SANTOS, G. P. N.; ARAÚJO, F. S.; NETO, H. F.; MONTEIRO, A. J. A. Danos em sementes de Cassia ferruginea causados por Zabrotes interstitialis, Pygiopachymerus lineola (Coleoptera: Bruchidae) e um Lepidoptera (Pyralidae). Revista Brasileira de Biologia, São Carlos, v. 54, n. 2, p. 311-316, 1994.

TOMAZ, C. A.; KESTRING, D.; ROSSI, M. N. Biological Research, Santiago, v. 40, n. 3, p. 281-290, 2007. 